12

\title{
Формирование кольцевых структур пучка при коллективном ускорении ионов в системе с диэлектрическим анодом
}

\author{
(C) В.С. Лопатин, Г.Е. Ремнев , А.А. Мартыненко
}

Национальный исследовательский Томский политехнический университет 『 E-mail: remnev06@mail.ru

Поступило в Редакцию 23 декабря 2016 г.

Представлены результаты экспериментального исследования коллективного ускорения протонов и дейтронов в электронном пучке из плазмы, образуемой на поверхности диэлектрической вставки анода. В исследованиях использован импульсный электронный ускоритель с ускоряющим напряжением до $1 \mathrm{MV}$, током до $40 \mathrm{kA}$, длительностью импульса $50 \mathrm{~ns}$. Снижение длительности фронта ускоряющего напряжения, оптимизация диодного узла и области дрейфа обеспечили формирование нескольких кольцевых образований электронионного пучка. В кольце диаметром $4.5 \mathrm{~cm}$ и шириной $0.2 \mathrm{~cm}$ наблюдалось до $50 \%$ наведенной в медной мишени радиоактивности. Обнаружена связь формирования высокой плотности энергии в кольцевых отпечатках и аксиальной компоненты собственного магнитного поля электронного пучка с повышением эффективности ускорения наиболее интенсивной группы ионов.

DOI: 10.21883/PJTF.2017.10.44616.16632

В результате экспериментальных исследований ускорения ионов релятивистскими электронными пучками (РЭП) [1,2] лучшие результаты были получены в системе с диодом Люса [3], содержащим острийный катод и диэлектрическую вставку в аноде. Эффективное ускорение ионов наблюдалось только при токе РЭП, превышающем предельный ток в вакууме. Установлена определенная пропорциональная зависимость максимальной энергии ионов $E_{\max }$ от величины ускоряющего напряжения. „Длина ускорения“, как правило, не превышала $10 \mathrm{~cm}$ [2], наблюдалось снижение энергии ионов $E_{p}$ при увеличении длины эквипотенциальной области дрейфа электронного пучка [4]. В вакуумной камере с лайнерами-линзами [5] наблюдалось 


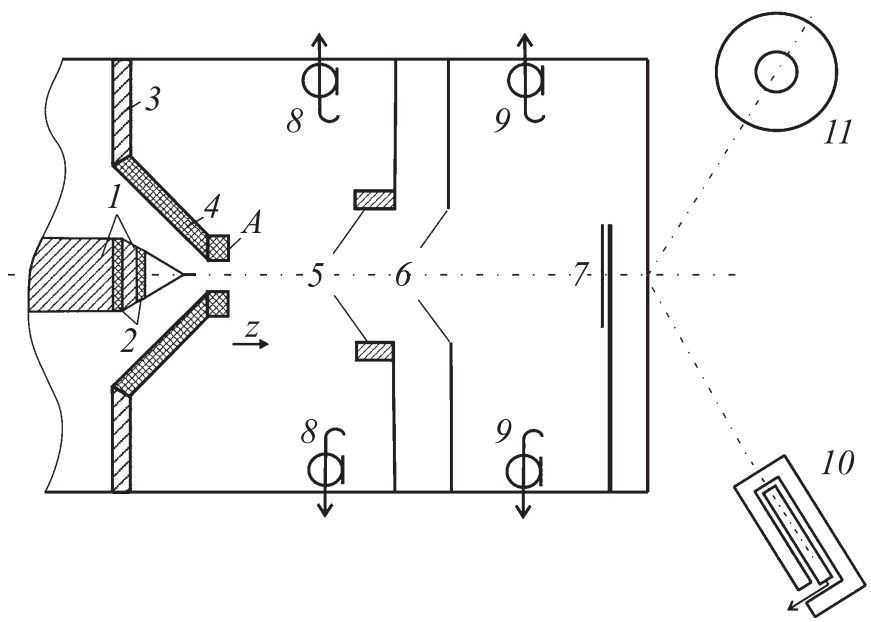

Рис. 1. Схема эксперимента: 1 - катод, $2-$ диэлектрические вставки; 3, 4 - анод; $A-$ сменная вставка; $5-$ линза, $6-$ экран, $7-$ коллектор или мишень, 8,9- магнитные зонды, 10 - сцинтилляционный детектор, $11-$ активационный детектор нейтронов.

увеличение энергии ионов. В работе [6] обсуждались возможности управления синхронизмом перемещения виртуального катода с ионами с целью увеличения энергии ионов. В большинстве экспериментальных работ обнаружено наличие двух групп ускоренных протонов: низкоинтенсивной $\left(10^{10}-10^{12}\right.$ частиц) с максимальной энергией $E_{\max }$ до $50 \mathrm{eV}_{0}$ и более интенсивной $\left(10^{13}-10^{14}\right.$ частиц) с энергией $2-3 e V_{0}$ (e - заряд электрона, $V_{0}-$ ускоряющее напряжение). До настоящего времени механизмы ускорения ионов остаются невыясненными. Имеет место противоречивость данных в работах разных авторов. Для управления процессом коллективного ускорения ионов требуются дополнительные экспериментальные исследования, чему и посвящена данная статья.

Схема экспериментов представлена на рис. 1. Рабочая камера выполнена в виде медного цилиндра с диаметром и длиной $30 \mathrm{~cm}$. В отдельных экспериментах присоединялся патрубок длиной $40 \mathrm{~cm}$ и диаметром $9 \mathrm{~cm}$. Рабочее давление $(1-2) \cdot 10^{-4}$ Torr. Эксперименты

2* Письма в ЖТФ, 2017, том 43, вып. 10 
проведены с коническим катодом 1 , анодом с диэлектрической центральной вставкой из дейтерированного полиэтилена в виде полого конуса 2. В работе использован электронный ускоритель с ускоряющим напряжением $V_{0} \leqslant 1 \mathrm{MV}$, током пучка $I_{e}=30-40 \mathrm{kA}$, длительностью импульса $t=50 \mathrm{~ns}$ на полувысоте. Диэлектрическая часть анода 4 выполнена из фторопласта с большим диаметром конуса до $8 \mathrm{~cm}$. Для ускорения протонов или дейтронов устанавливалась вставка $A$ из обычного или дейтерированного полиэтилена. В этой геометрии диода практически весь ток электронов после пробоя поверхности анодного диэлектрика инжектировался сквозь анодное отверстие и многократно превосходил предельный ток в вакууме.

Воспроизводимость ускорительного процесса и предварительная оценка энергии ускоренных ионов проводились по нейтронному выходу $Y_{n}$, измеряемого после каждого срабатывания серебряноактивационным детектором 11 , из литиевой, медной, алюминиевой и в отдельных случаях из графитовой мишеней. Собственные магнитные поля (СМП) электронного пучка $B_{\varphi}$ и $B_{z}$ измерялись интегрирующими многовитковыми зондами 8,9 с постоянной времени $1.6 \mu \mathrm{s}$. Зонды устанавливались на боковых окнах вакуумной камеры и были защищены металлическими экранами от попадания электронов пучка.

Азимутальная симметрия РЭП и плазмы многоканального поверхностного пробоя анодного диэлектрика достигались путем обострения фронта ускоряющего напряжения диода предымпульсным газовым разрядником и разрядником с пробоем по поверхности диэлектрика. Сравнение нейтронных выходов из медной и графитовой мишеней, установленных на расстоянии $Z=10 \mathrm{~cm}$, привело к выводу об ускорении $5 \cdot 10^{12}$ протонов с энергией $E_{p}=25 \mathrm{MeV}$. Активационные измерения были затруднены значительным испарением мишени при воздействии пучка. Максимальная энергия снижалась с удалением мишени от анода до $E_{p \max }=16 \mathrm{MeV}$ при $Z=20 \mathrm{~cm}$. Ускорение протонов до $E_{p}=6-6.5 \mathrm{MeV}$ в количестве $N_{p}=(2-3) \cdot 10^{14}$ и дейтронов до $E_{d \text { mid }}=4-4.5 \mathrm{MeV}, N_{d}=(3-4) \cdot 10^{14}$ измерено при $Z=34 \mathrm{~cm}$ методом активации стопы фольг в реакциях ${ }^{63} \mathrm{Cu}(p, n){ }^{63} \mathrm{Zn}$ и ${ }^{27} \mathrm{Al}(d, p){ }^{28} \mathrm{Al}$. Вычисленный суммарный продольный импульс ионов превышал импульс РЭП в 4-8 раз, что предполагает передачу импульса в продольных осцилляциях электронов. В многократной передаче импульса могла участвовать часть электронов, не высыпавшаяся на стенки камеры, удерживаемая $B_{z}$-компонентой СМП. Подобие осциллограмм зондов

Письма в ЖТФ, 2017, том 43, вып. 10 


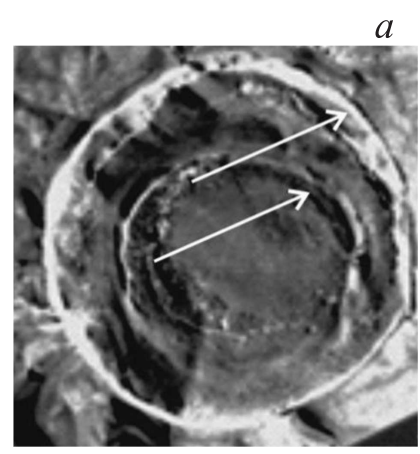

$1 \mathrm{~cm}$

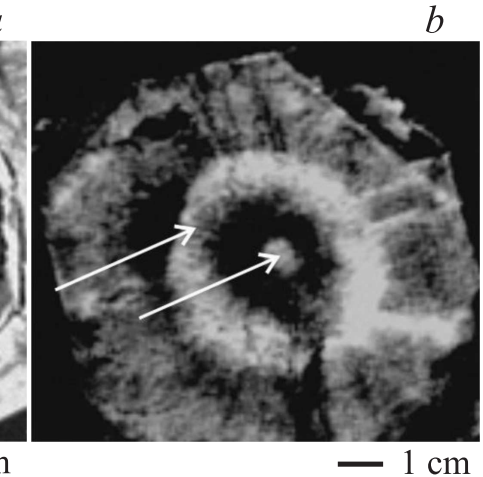

Рис. 2. Медные мишени, установленные на расстоянии: $a-Z=10 \mathrm{~cm}$ и $b-40 \mathrm{~cm}$. Стрелки указывают на повышенную плотность энергии в отпечатках.

$B_{z}$-поля и ионных токов на коллекторах, свидетельствующее о связи явлений формирования $B_{z}$-поля и ускорения ионов, отмечалось ранеe [7].

В электронном пучке, инжектированном в анодное отверстие, при его дальнейшем распространении выделялось до 4 концентрических зон с различной плотностью энергии, наблюдаемых по повреждению поверхности металлических и диэлектрических мишеней. В условиях стабильного ускорения ионов эти зоны имели вид замкнутых колец.

После прохождения анодного отверстия и захвата ионов из плазмы электронный пучок уже включал ионы, что позволило его рассматривать как электрон-ионный пучок. Условия стабилизации ускорения ионов совпадали с условиями образования колец высокой плотности тока на мишенях. Число и диаметры колец, интенсивность потока энергии в них и радиальная ширина этих отпечатков зависели от размеров и материала анодной вставки, величины анод-катодного зазора, наличия линз за анодом. Изменения конфигурации отпечатков сопровождались изменением величины $B_{z}$-компоненты СМП. На рис. 2 представлены медные мишени с участками повреждений. Заметны несколько кольцевых зон с разным уровнем плотности энергии электрон-протонного пучка (отмечены стрелками). По мере удаления мишеней от анода их

Письма в ЖТФ, 2017, том 43, вып. 10 

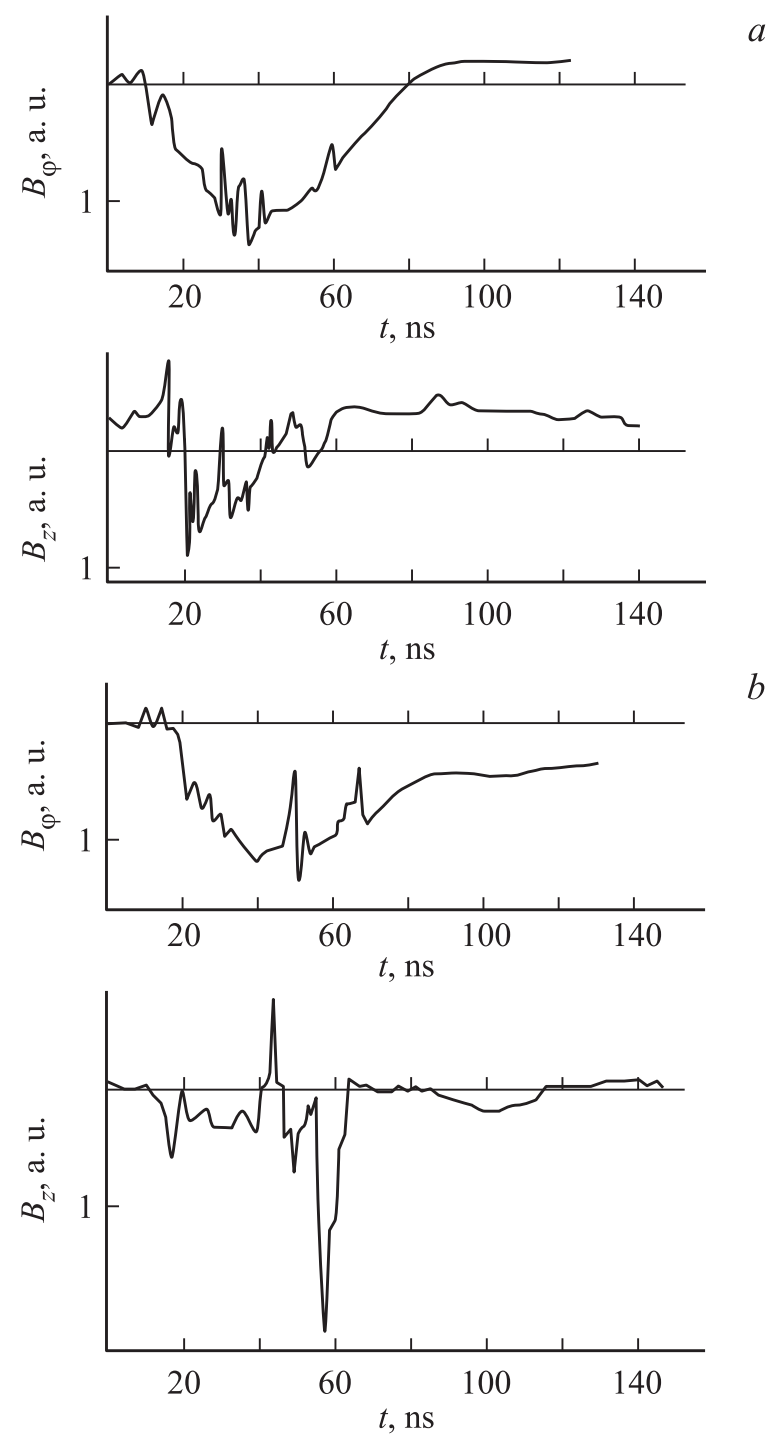

Рис. 3. Собственные магнитные поля (зонд 9): $a-$ в камере без линзы; $b-$ позади линзы.

Письма в ЖТФ, 2017, том 43, вып. 10 
диаметр возрастал, между зонами испарения появлялись области без заметного нагрева. Необходимо отметить, что формирование кольцевого отпечатка наблюдалось и в работе [8], где размер кольца определялся диаметром катода.

При размещении линзы на расстоянии $8-10 \mathrm{~cm}$ от анода амплитуда сигнала $B_{z}$-компоненты СМП возрастала более чем в 2 раза на зондах 8 и 9. Из сравнения показаний $B_{\varphi}$-зондов на рис. $3, a$ и $b$ видно, что амплитуда тока РЭП изменялась незначительно. Усиленная в результате взаимодействия с линзой $B_{z}$-компонента создает магнитную пробку, и РЭП распространяется вперед после ее спада (рис. $3, b$ ).

Измеренная плотность радиоактивных ядер ${ }^{63} \mathrm{Zn}$ в области узких кольцевидных отпечатков, появляющихся на мишени после установки линзы, была до 15 раз выше, чем в остальной части. Так, в кольце диаметром $4.5 \mathrm{~cm}$ и шириной менее $0.2 \mathrm{~cm}$ наблюдалось $50 \%$ всей наведенной радиоактивности медной мишени, расположенной на расстоянии $Z=34 \mathrm{~cm}$ от анода.

Протоны с $E_{\max } \geqslant 46 \mathrm{MeV}, N=(2-3) \cdot 10^{10}$ в импульсе длительностью $5 \mathrm{~ns}$ двигались вблизи оси системы и регистрировались коллектором на расстоянии $60 \mathrm{~cm}$ от анода после прохождения медного экрана толщиной $3.5 \mathrm{~mm}$. Величина $E_{\max }$ определялась также по окраске щелочно-галоидных кристаллов $\mathrm{LiF}$ и $\mathrm{KCl}$ при возбуждении протонами М-центров.

Совпадение количества и относительной амплитуды максимумов $B_{z}$-компоненты и протонных импульсов на коллекторах [7], формирование кольцевых отпечатков на мишенях, повышенная плотность радиоактивности кольцевых зон указывают на ускорение основного количества ионов в нескольких трубчатых образованиях, поступающих на мишень последовательно по времени. Представляется, что в [4] и в работах других авторов, определявших „длину ускорения“, перемещение мишени могло приводить к изменению $B_{z}$-компоненты СМП, что изменяло условия ускорения ионов.

Таким образом, в данной работе установлена связь трубчатых структур электрон-ионного пучка с ускорением основной группы ионов. Их возникновение и распространение в вакуумированной камере тесно связано с собственными магнитными полями пучка.

Данная работа поддержана грантом Российского научного фонда № 14-19-00439.

Письма в ЖТФ, 2017, том 43, вып. 10 


\section{Список литературы}

[1] Плютто А.А., Суладзе К.В., Рыжкков В.Н. // Письма ЖЭТФ. 1967. Т. 6. C. $540-541$.

[2] Плютто А.А. Ускорение ионов в электронных пучках. Саратов, 2007.

[3] Luce J.S., Sahlin H., Crites N.R. // IEEE Trans. Nucl. Sci. 1973. NS-20. P. 336340.

[4] Bistritscy V.M. et al. // IEEE Trans. Nucl. Sci. 1979. V. 26. N 3. P. 4248-4250.

[5] Zorn G.T., Kim H., Boyer C.N. // IEEE Trans. Nucl. Sci. 1975. NS-22. P. 1006.

[6] Дубинов А.Е., Корнилова И.Ю., Селемир В.Д. // УФН. 2002. Т. 172. № 11. C. $1225-1248$.

[7] Didenko A.N., Logachev E.I., Lopatin V.S., Remnev G.E. // Proc. XI Intern. Simp. Dich. and Electr. Insul. in Vacuum. Berlin, GDR, 1984. P. 385-389.

[8] Челпанов В.И., Голяков П.И., Корнилов В.Г. и др. // ЖТФ. 2009. 79(1). Р. 144. 